\title{
Equilibrium, Thermodynamic and Mechanism Studies of Malachite Green adsorption on Used Black Tea Leaves from Acidic Solution
}

\author{
Mohammad Abul Hossain*, Md. Lokman Hossain and Tanim-al-Hassan \\ Department of Chemistry, University of Dhaka, Dhaka-1000, Bangladesh \\ E-mail: hossainabul@yahoo.com
}

\begin{abstract}
Keywords: Malachite Green, Used Black Tea Leaves, Acidic Media, Isotherms Modeling, Thermodynamics, Electrolytes, Adsorption Mechanism.
\end{abstract}

\begin{abstract}
This study reports the equilibrium adsorption mechanism and thermodynamics for the removal of Malachite Green (MG) from acidic solution using Used Black Tea Leaves (UBTL) as a low cost adsorbent. The effect of initial dye concentration, processing temperature and the presence of electrolytes on the adsorption from acidic solutions were investigated in batch process. Adsorption process was attained to the equilibrium at about 24 hours. Adsorption isotherms of MG on UBTL for different temperatures were constructed at $\mathrm{pH} 2.0$ and the equilibrium adsorption data were analyzed using different model equations such as Langmuir, Freundlich, Temkin, DubininRadushkevich (D-R), Harkin-Jura, Halsey, Elovich-Larionov and Flory-Huggens isotherms. The experimental results were reasonably correlated by Langmuir, Flory-Huggins and D-R models than other isotherm models. The maximum adsorption capacity $\left(q_{\mathrm{m}}\right)$, intensity of adsorption $(b)$ and separation factor $\left(R_{\mathrm{b}}\right)$ were calculated from Langmuir plot and activation energy of adsorption $\left(E_{\mathrm{ad}}\right)$ was determined from D-R isotherm. At $\mathrm{pH} 2.0$, the equilibrium adsorption capacity of UBTL to MG is $110 \mathrm{mg} \cdot \mathrm{g}^{-1}$ at $30^{\circ} \mathrm{C}$, which was increased with increasing temperature suggested endothermic nature of adsorption. Thermodynamics parameters: $\Delta G_{\text {ads }}, \Delta H_{\text {ads }}$ and $\Delta S_{\text {ads }}$ were calculated from Langmuir constant $(b)$. The positive values of enthalpy and free energy, and negative value of entropy suggested that the adsorption is less spontaneous and surface migration or fragmentation of MG molecules on UBTL surface might be occur. Again, the low value of activation energy of adsorption $\left(E_{\mathrm{ad}}=0.3 \mathrm{~kJ} \cdot \mathrm{mol}^{-1}<8 \mathrm{~kJ} \cdot \mathrm{mol}^{-1}\right)$ suggested that the adsorption is controlled by physical in nature. A possible mechanism involvement of protonation is proposed from the effect of electrolytes during the adsorption of MG on UBTL at $\mathrm{pH} 2.0$.
\end{abstract}

\section{Introduction}

Most of the dyes are toxic and carcinogenic compounds. These are widely used in different industries like food, acrylic, paint, paper, leather, drugs, petroleum and plastic. MG is one of these that is difficult to biodegrade and remove from waste water due to its complex aromatic structures [1]. There are several techniques to apply for removal of dyes from waste water such as chemical, biological and physical process [2]. Due to economic reasons, adsorption is the best process for removal of different pollutants from waste water [3]. Several kinds of low cost adsorbents such as buffing dust of leather industry [4], coconut husk [5], wheat bran [6], vetiver roots [7], date stones [8-9], pistachio nut shell [10], apple promace and wheat straw [11] were studied to evaluate their applicability for the removal of dyes from aqueous solutions by adsorption process. In recent year, high adsorption capacity of used black tea leaves (UBTL) as a low cost adsorbent to Cr(VI) [12-14] and dyes [15-20] were reported.

Therefore, the aim of the present research work was to evaluate the applicability of UBTL as an adsorbent for the removal of Malachite Green (MG) from aqueous solution by investigating the equilibrium capacity and adsorption mechanism. The effects of different variables such as contact time, initial concentration of dye, processing temperature and the presence of electrolytes were studied. Then, the equilibrium adsorption data were analyzed by using different model isotherm equations. Thermodynamic parameters and effect of electrolytes on the adsorption were investigated to elucidate the mechanism of the adsorption of MG on UBTL. 


\section{Materials and Methods}

\subsection{Adsorbent}

The fresh tea leaves were collected from Dhaka city in Bangladesh. The UBTL were prepared as described elsewhere [15]. The UBTL were sieved through the metallic sieve of particle size $0.425 \mathrm{~mm}$ and $0.500 \mathrm{~mm}$ and stored in air tight bottles which were kept into a desiccator for desired adsorption experiments.

\subsection{Adsorbate}

Malachite Green is an aromatic basic dye and commonly used in dyeing of cotton, silk, paper, bamboo, weed, straw and leather as well as in manufacturing of paints and printing inks. Malachite Green is a green crystalline powder with chemical formula of $\left.\left[\mathrm{C}_{6} \mathrm{H}_{5} \mathrm{C}\left(\mathrm{C}_{6} \mathrm{H}_{4} \mathrm{~N}_{(} \mathrm{CH}_{3}\right)_{2}\right)_{2}\right] \mathrm{Cl}$. Its IUPAC name is 4-[(4-dimethylaminophenyl)phenyl-methyl]- $N, N$-dimethyl aniline. Aniline Green, Basic Green 4, Diamond Green B and Victoria Green B are synonyms of Malachite Green. Molecular mass of MG is $382.93 \mathrm{~g} \cdot \mathrm{mol}^{-1}$. The structural formula of Malachite Green is shown in Fig. 1. A stock solution of dye was prepared by dissolving $1.0 \mathrm{~g}$ of MG (Analytical grade) in distilled water into a $1000 \mathrm{~mL}$ volumetric flask from which desired concentrated solutions were prepared for adsorption study. Malachite Green in solution was analyzed at predetermined $\lambda_{\max }=$ $617 \mathrm{~nm}$ and at optimum $\mathrm{pH}$ 4.0. All the chemicals were used in this present study of analytical reagent grade.<smiles>CN(C)c1ccc(C(=C2C=CC(=[N+](C)[O-])C=C2)c2ccccc2)cc1</smiles>

Fig. 1. Structural formula of Malachite Green.

\subsection{Determination of equilibrium time}

For determination of equilibrium time, $0.0015 \mathrm{~g}$ UBTL (425-500 $\mu \mathrm{m}$ in diameter size) was taken in $25 \mathrm{~mL}$ of about $110 \mathrm{mg} \cdot \mathrm{L}^{-1} \mathrm{MG}$ solution in each of the adsorption bottles. Before addition of UBTL, $\mathrm{pH}$ of MG solution was adjusted at predetermined optimum $\mathrm{pH} 2.0$ by drop-wise addition of $0.05 \mathrm{~mol} \cdot \mathrm{L}^{-1} \mathrm{HNO}_{3}$ or $0.05 \mathrm{~mol} \cdot \mathrm{L}^{-1} \mathrm{NaOH}$ solutions. All bottles were shaken in a thermostated mechanical shaker (NTS-4000 EYELA, Japan) at constant temperature of $30^{\circ} \mathrm{C}$. The bottles were individually taken out from the shaker after 15, 45, 60, 120, 240 and 360 minutes of shaking. After adsorption, the UBTL was separated from the mixtures. The separated solutions were diluted as required concentration within the calibration limit and $\mathrm{pH}$ of the diluted solutions were adjusted at 4.0 before measuring their absorbance using UV-vis spectrophotometer (Model 1800A, Shimadzu) at $617 \mathrm{~nm}$, due to the construction of calibration curve at $\mathrm{pH} \mathrm{4.0.} \mathrm{The} \mathrm{amounts} \mathrm{of} \mathrm{MG} \mathrm{adsorbed} \mathrm{on}$ to UBTL at different contact times were calculated using the following Eq. 1,

$$
q_{\mathrm{t}}=\left(C_{\mathrm{i}}-C_{\mathrm{t}}\right) \times \frac{V}{W}
$$

where $C_{\mathrm{i}}$ and $C_{\mathrm{t}}$ are the concentrations of MG $\left(\mathrm{mg} \cdot \mathrm{L}^{-1}\right)$ at zero time and at time $t$, respectively. $V$ is the volume of solution in liter and $W$ is the weight of the dry UBTL in g. The amount adsorbed is plotted against the contact time as shown in Fig. 2 from where equilibrium time was found to 24 hours. 


\subsection{Determination of adsorption isotherms at different temperatures}

To determine adsorption isotherms at optimum $\mathrm{pH}, 7$ bottles containing each of $0.0015 \mathrm{~g}$ UBTL into $25 \mathrm{~mL} \mathrm{MG} \mathrm{solution} \mathrm{of} \mathrm{various} \mathrm{concentrations} \mathrm{ranging} \mathrm{from} 25$ to $900 \mathrm{mg} \cdot \mathrm{L}^{-1}$ of $\mathrm{MG}$ solutions, have been shaken at $30^{\circ} \mathrm{C}$ for 24 hours which was the equilibrium time determined in last section. After adsorption, the residual concentrations of MG in each bottles, were analyzed by UVvis spectrophotometer using same procedure described. The amount adsorbed was calculated for different initial concentrations of MG and respective equilibrium concentration was determined to construct the adsorption isotherm. To obtain adsorption isotherms at optimum $\mathrm{pH}$ for different temperatures, similar experiments were repeated at temperatures 35,40 and $50^{\circ} \mathrm{C}$. Each temperature was controlled within $\pm 0.5^{\circ} \mathrm{C}$. Adsorption isotherms at different temperatures are shown in Fig. 3 .

\subsection{Determination the effect of electrolyte}

To establish the adsorption mechanism, the effect of electrolyte on the adsorption of MG on UBTL was determined. Two separate adsorption experiments at initial $\mathrm{pH} 2.0$ using fixed initial concentration of $97.623 \mathrm{mg} \cdot \mathrm{L}^{-1}$ of $\mathrm{MG}$ at $30^{\circ} \mathrm{C}$, were performed with different amounts of $\mathrm{NaCl}$ and $\mathrm{NaNO}_{3}$ keeping other parameters constant. Experimental results are presented as amount adsorbed of MG on UBTL as a function of electrolytes concentration.

\section{Results and Discussion}

\subsection{Estimation of equilibrium time}

The equilibrium time for an adsorption process occurs when rate of adsorption and desorption is equal. The amount adsorbed is being steady value with time after reaching equilibrium. Estimation of equilibrium time is very important for construction of adsorption isotherm. Fig. 2 shows the variation of amount adsorbed of MG on UBTL with contact time. From this figure, the equilibrium time was determined at minimum change of amount adsorbed with time which is about 24 hours.

\subsection{Adsorption isotherm}

Adsorption isotherms are used to study the interaction between the adsorbent surface and the adsorbate molecules. The amount of $\mathrm{MG}$ adsorbed at equilibrium with the equilibrium concentration of MG on UBTL at different temperature and $\mathrm{pH} 2.0$ are presented in Fig. 3. Different isotherm model equations such as Langmuir, Freundlich, Temkin, D-R, Harkin-Jura, Halsey, Elovich-Larionov and Flory-Huggens were used to verify their applicability to evaluate the nature of adsorption.

\section{Langmuir Isotherm}

The Langmuir isotherm assumes monolayer surface coverage on equivalent sites [21]. The Langmuir isotherm model has been successfully applied to many adsorbate pollutants adsorbed on different adsorbents such as tamarix aphylla leaves [22], citrullus lanatus rind [23], raw moroccan clay [24] and chemically modified silica gel [25]. The linear form of the Langmuir isotherm equation is given by Eq. 2,

$$
\frac{C_{\mathrm{e}}}{q_{\mathrm{e}}}=\frac{1}{q_{\mathrm{m}} b}+\frac{C_{\mathrm{e}}}{q_{\mathrm{m}}}
$$

where, $C_{\mathrm{e}}\left(\mathrm{mg} \cdot \mathrm{L}^{-1}\right)$ is the equilibrium concentration of $\mathrm{MG}, q_{\mathrm{e}}\left(\mathrm{mg} \cdot \mathrm{g}^{-1}\right)$ is the amount of $\mathrm{MG}$ adsorbed at equilibrium, $q_{\mathrm{m}}\left(\mathrm{mg} \cdot \mathrm{g}^{-1}\right)$ and $b\left(\mathrm{~L} \cdot \mathrm{mg}^{-1}\right)$ is Langmuir constant related to adsorption efficiency and the rate of adsorption. The linear plot of $C_{\mathrm{e}} / q_{\mathrm{e}} \mathrm{vs} C_{\mathrm{e}}$ is shown in Fig. 4 and the values of $q_{\mathrm{m}}$ and $b$ were determined from the slope and the intercept of the plots for different temperatures and are presented in Table 1 . It shows that the adsorption capacity $\left(q_{\mathrm{m}}\right)$ of UBTL for MG is 109.89 $\mathrm{mg} \cdot \mathrm{g}^{-1}$ at $30^{\circ} \mathrm{C}$ which is increased to $588.24 \mathrm{mg} \cdot \mathrm{g}^{-1}$ at $50^{\circ} \mathrm{C}$. 


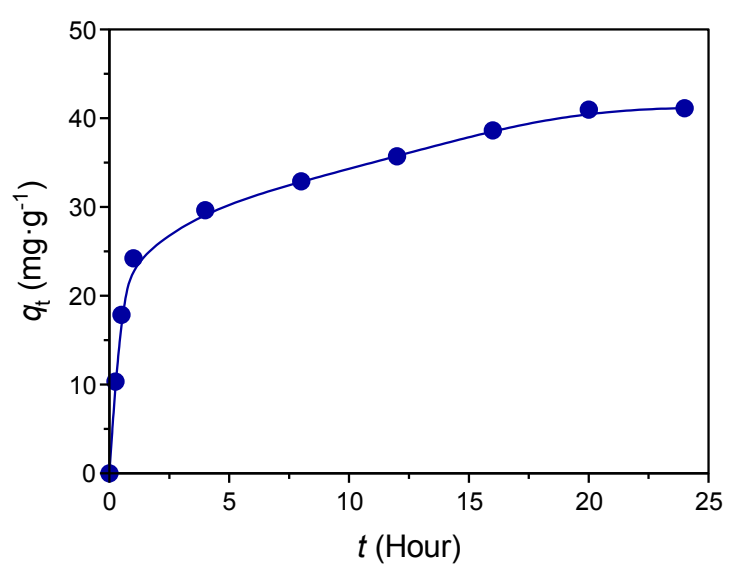

Fig. 2. Change of amount adsorbed of MG on UBTL with time for the initial concentration of $110.012 \mathrm{mg} \cdot \mathrm{L}^{-1}$ at $\mathrm{pH} 2.0$ and $(30 \pm 0.2)^{\circ} \mathrm{C}$.

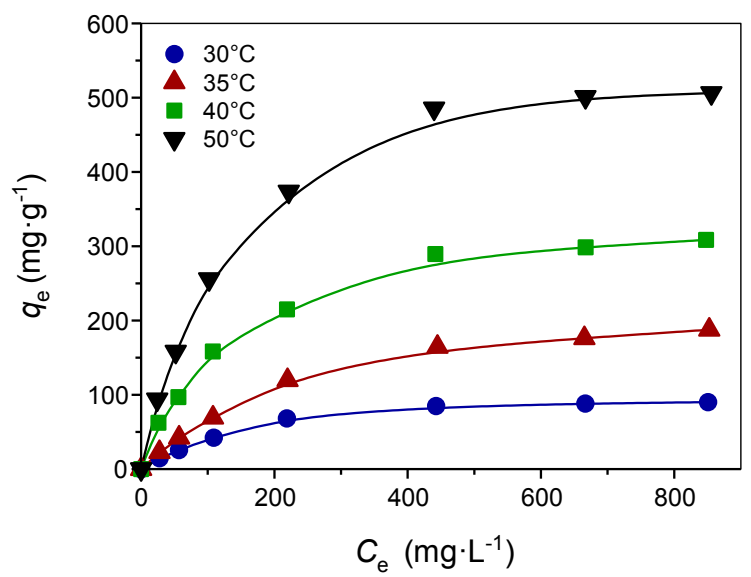

Fig. 3. Adsorption isotherms of MG on UBTL for different temperature at $\mathrm{pH} 2.0$.

Separation factor. The feasibility of the adsorption isotherm is described by the essential characteristics of the Langmuir isotherm which can be expressed in terms of dimensionless constant called separation factor, $R_{\mathrm{b}}[26]$ by the Eq. 3 as

$$
R_{b}=\frac{1}{1+b C_{\mathrm{o}}}
$$

The values of $R_{\mathrm{b}}$ indicate the nature of the adsorption isotherm to be unfavorable $\left(R_{\mathrm{b}}>1\right)$, favorable $\left(0<R_{\mathrm{b}}<1\right)$, linear $\left(R_{\mathrm{b}}=1\right)$ or unfavorable $\left(R_{\mathrm{b}}=0\right)$. A plot of the calculated $R_{\mathrm{b}}$ values vs $C_{\mathrm{o}}$ at different temperature is presented in Fig. 5. The $R_{\mathrm{b}}$ values for the adsorption of MG onto UBTL lies between 0 to 1 , indicating that the adsorption is a favorable [27].

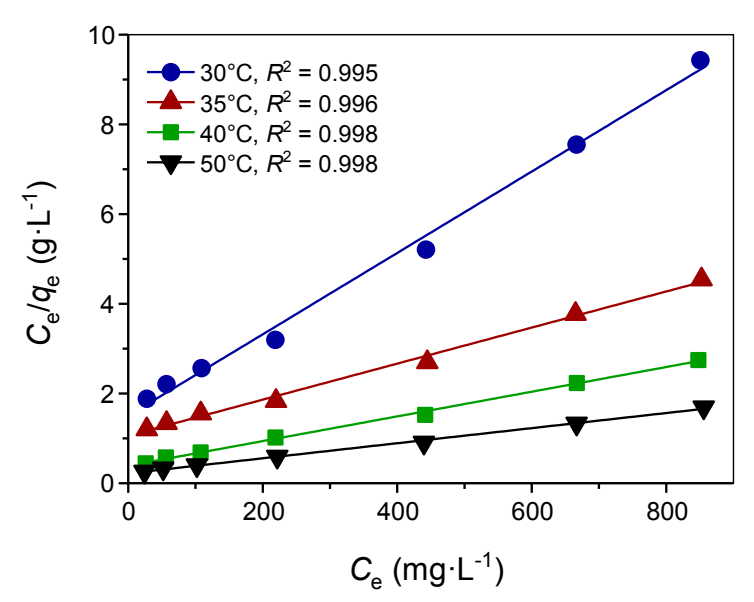

Fig. 4. Linear plot of Langmuir isotherm for the adsorption of MG on UBTL at $\mathrm{pH} 2.0$ for different temperatures.

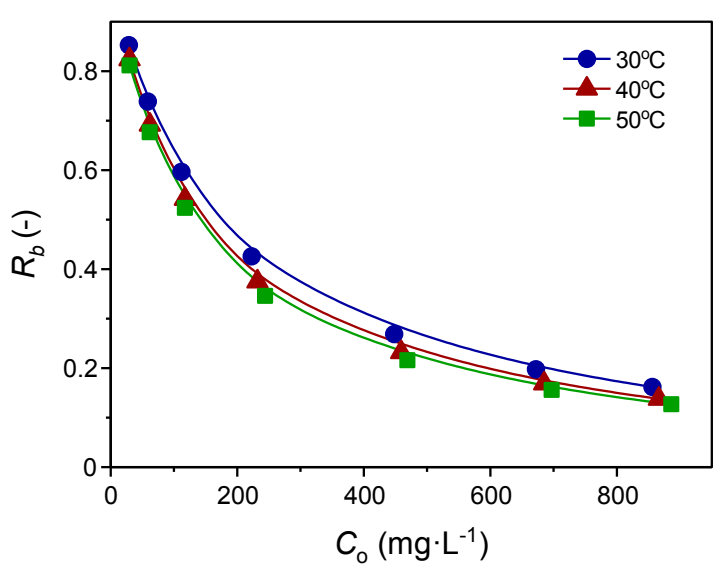

Fig. 5. Effect of initial concentration of $M G$ on on dimensionless separation factor, $R_{\mathrm{b}}$ at $\mathrm{pH}$ 2.0 and different temperatures.

\section{Freundlich Isotherm}

The Freundlich isotherm equation assumes a heterogeneous adsorption surface with sites that have different energies of adsorption and are not equally available. The Freundlich isotherm is expressed by the Eq. 4 [28],

$$
\ln q_{\mathrm{e}}=\ln k_{\mathrm{f}}+1 / n \ln C_{\mathrm{e}}
$$


where, $k_{\mathrm{f}}\left(\mathrm{mg} \cdot \mathrm{g}^{-1}\right)$ and $n$ are Freundlich constants related to adsorption capacity and adsorption intensity, respectively. A plot of $\ln q_{\mathrm{e}}$ vs $\ln C_{\mathrm{e}}$ is shown in Fig. 6 and the values of $k_{\mathrm{f}}$ and $n$ were calculated from the intercept and the slope of the plot and are presented at Table 1 . The values of $n>1$ indicate the favorable adsoption process [29].

\section{Temkin isotherm}

The Temkin isotherm equation assumes that the heat of adsorption of all the molecules in layer decreases linearly with coverage due to adsorbent-adsorbate interactions, and that the adsorption is characterized by a uniform distribution of the bonding energies, up to some maximum binding energy [30]. The Temkin isotherm is generally given by the following Eq. 5,

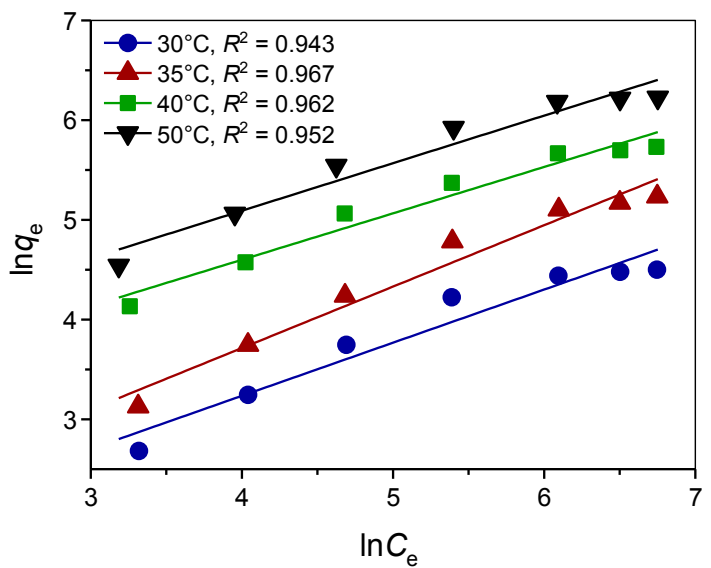

Fig. 6. Freundlich isotherm for the adsorption of MG on UBTL at $\mathrm{pH} 2.0$ for different temperatures.

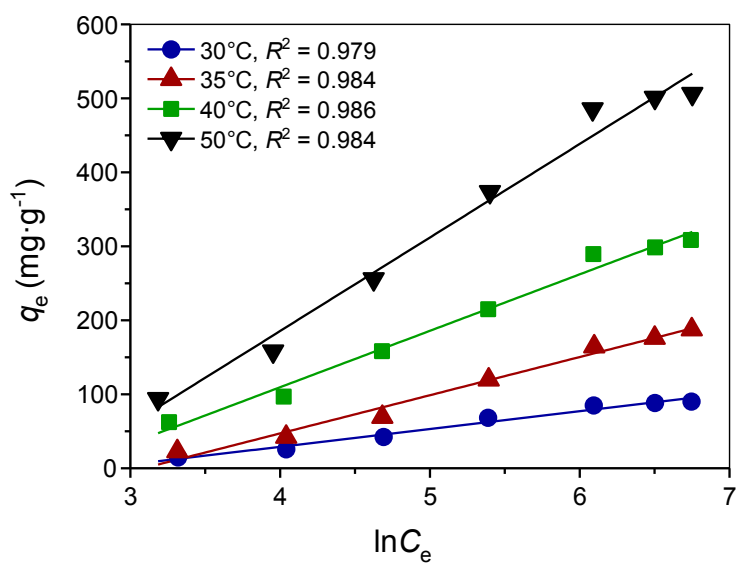

Fig. 7. Temkin isotherm for the adsorption of MG solution on UBTL at $\mathrm{pH} 2.0$ for different temperatures.

$$
q_{\mathrm{e}}=\frac{R T}{b_{\mathrm{T}}} \ln \left(k_{\mathrm{T}} C_{\mathrm{e}}\right)
$$

where, $T$ is the absolute temperature $(\mathrm{K}), R$ is the universal gas constant $\left(8.314 \mathrm{~J} \cdot \mathrm{mol}^{-1} \cdot \mathrm{K}^{-1}\right), k_{\mathrm{T}}$ is the equilibrium binding constant $\left(\mathrm{L} \cdot \mathrm{mg}^{-1}\right)$ corresponding to the maximum binding energy and $b_{\mathrm{T}}$ is the variation of adsorption energy $\left(\mathrm{kJ} \cdot \mathrm{mol}^{-1}\right)$. The linear form of this model is given by Eq. 6 as follows [31].

$$
q_{\mathrm{e}}=B \ln k_{\mathrm{T}}+B \ln C_{\mathrm{e}}
$$

where $B=R T / b_{\mathrm{T}}$ is the Temkin constant related to the heat of adsorption $\left(\mathrm{J} \cdot \mathrm{mol}^{-1}\right)$. The values of $k_{\mathrm{T}}$ and $B$ were calculated from the intercept and the slope of the linear plot of $q_{e} \operatorname{vs} \ln C_{e}$ as shown in Fig. 7. The values are presented in Table 1 where the values of $B$ indicated that the heat of adsorption increases with temperature. So, the adsorption process is endothermic [32].

\section{Dubinin-Radushkevich (D-R) isotherm}

Dubinin-Radushkevich have reported a isotherm model where adsorption occurs on both homogenous and heterogeneous surfaces [33]. It is applied to estimate characteristics porosity and apparent free energy of adsorption. The linear form of the D-R isotherm is given as Eq. 7,

$$
\ln q_{\mathrm{e}}=\ln q_{\mathrm{DR}}-\gamma \varepsilon^{2}
$$

where, $q_{\mathrm{DR}}$ is the D-R adsorption capacity $\left(\mathrm{mg} \cdot \mathrm{g}^{-1}\right), \gamma$ is the activity coefficient $\left(\mathrm{mol}^{2} \cdot \mathrm{k}^{-1} \cdot \mathrm{J}^{-2}\right)$ related to the mean free energy of adsorption and $\varepsilon$ is Polanyi potential which is calculated by Eq. 8 as 


$$
\varepsilon=R T \ln \left(1+\frac{1}{C_{\mathrm{e}}}\right)
$$

The linear plot of $\ln q_{\mathrm{e}} \mathrm{vs} \varepsilon^{2}$ is shown in Fig. 8 and the values of $\gamma$ and $q_{\mathrm{DR}}$ were determined from the slope and the intercept of the plot and are presented in Table 1. The value of $\gamma$ decreases with increasing of temperature due to strengthening of adsorbate-adsorbent interaction for the above system [34].

The mean free energy of adsorption, $E\left(\mathrm{~kJ} \cdot \mathrm{mol}^{-1}\right)$ can be calculated from the Eq. 9,

$$
E=-\frac{1}{\sqrt{2 \gamma}}
$$

The $E$ values indicate the adsorption type, physical adsorption $\left(E<8 \mathrm{~kJ} \cdot \mathrm{mol}^{-1}\right)$ or chemical ion exchange $\left(E=16 \mathrm{~kJ} \cdot \mathrm{mol}^{-1}\right)$ or particle diffusion mechanism $\left(E>16 \mathrm{~kJ} \cdot \mathrm{mol}^{-1}\right)$ [35]. The adsorption energy, $E$ was found between $0.302-0.341 \mathrm{~kJ} \cdot \mathrm{mol}^{-1}$ which implies that the adsorption of MG on UBTL is controlled by physical in nature.

\section{Harkin-Jura isotherm}

The Harkin-Jura isotherm describes the multilayer adsorption system with the existence of a heterogeneous pore distribution in adsorbent surface [36]. The Harkin-Jura adsorption isotherm model is presented by Eq. 10,

$$
\frac{1}{q_{\mathrm{e}}^{2}}=\frac{B_{\mathrm{HJ}}}{A_{\mathrm{HJ}}}-\frac{1}{A_{\mathrm{HJ}}} \log C_{\mathrm{e}}
$$

where, $B_{\mathrm{HJ}}$ and $A_{\mathrm{HJ}}$ are the Harkin-Jura isotherm constants. The values of $B_{\mathrm{HJ}}$ and $A_{\mathrm{HJ}}$ are obtained from the intercept and slope of the plot of $1 / q_{\mathrm{e}}^{2}$ vs $\log C_{\mathrm{e}}$ as shown in Fig. 9 and values are presented in Table 1.

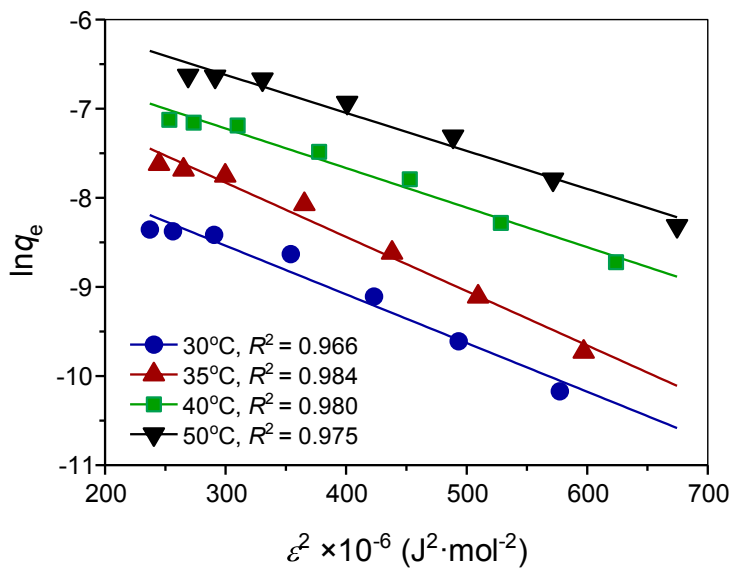

Fig. 8. D-R isotherms for adsorption of $M G$ on UBTL for different temperatures.

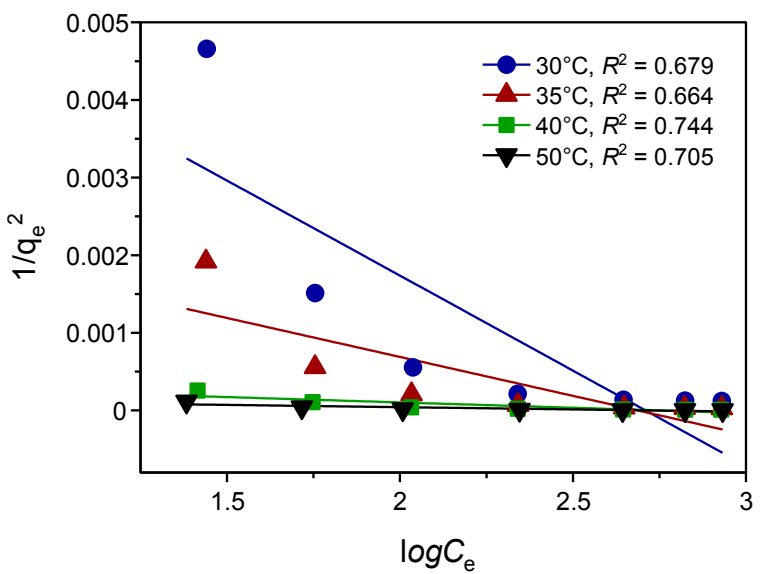

Fig. 9. Harkin-Jura isotherm for adsorption of MG on UBTL for different temperatures.

\section{Halsey isotherm}

The Halsey adsorption isotherm model mainly describes the multilayer adsorption system for the adsorbate at a relatively large distance with a heterogeneous porous nature of adsorbent surface [37]. The Halsey adsorption isotherm is given by Eq. 11, 


$$
\ln q_{\mathrm{e}}=\left(\frac{1}{n_{\mathrm{H}}}\right) \ln k_{\mathrm{H}}-\left(\frac{1}{n_{\mathrm{H}}}\right) \ln C_{\mathrm{e}}
$$

where, $k_{\mathrm{H}}$ and $n_{\mathrm{H}}$ are the Halsey constants. The values of $k_{\mathrm{H}}$ and $n_{\mathrm{H}}$ were calculated from the slope and the intercept of the linear plot of $\ln q_{\mathrm{e}} \mathrm{vs} \ln C_{\mathrm{e}}$, respectively as shown in Fig. 10 and the values are presented in Table 1. The experimental data are not applicable to the Halsey adsorption equation.

\section{Elovich-Larionov isotherm}

Elovich-Larionov isotherm describes the adsorption of non electrolytes from solution on solid surface. This isotherm can be expressed by Eq. 12 as [38-39],

$$
\ln \left(\frac{q_{\mathrm{e}}}{C_{\mathrm{e}}}\right)=\ln \left(k_{\mathrm{E}} q_{\mathrm{E}}\right)-\left(\frac{1}{q_{\mathrm{E}}}\right) q_{\mathrm{e}}
$$

where, $k_{\mathrm{E}}$ is the Elovich-Larionov isotherm constant and $q_{\mathrm{E}}$ is the maximum MG concentration on UBTL surface $\left(\mathrm{mg} \cdot \mathrm{g}^{-1}\right)$. The values of $q_{\mathrm{E}}$ and $k_{\mathrm{E}}$ were obtained from the slope and the intercept of the plot of $\ln \left(q_{\mathrm{e}} / C_{\mathrm{e}}\right)$ vs $q_{\mathrm{e}}$, respectively shown in Fig. 11 and the values are give in Table 1.

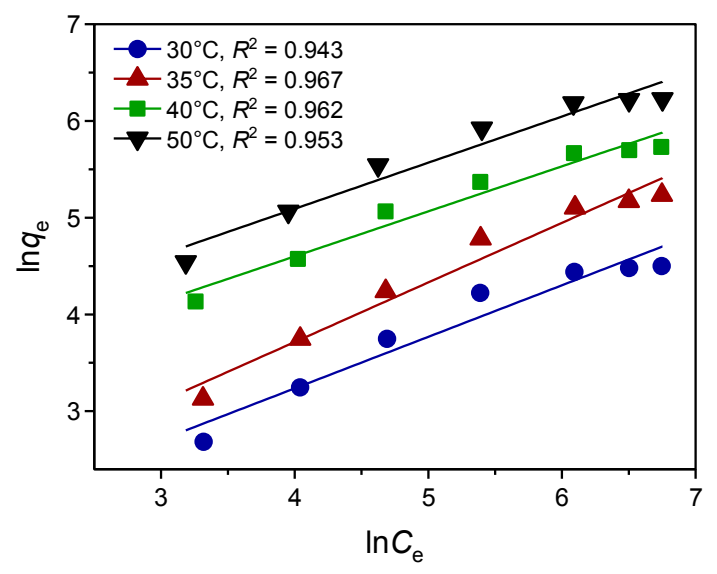

Fig. 10. Halsey isotherm for adsorption of $M G$ on UBTL for different temperatures at $\mathrm{pH} 2.0$.

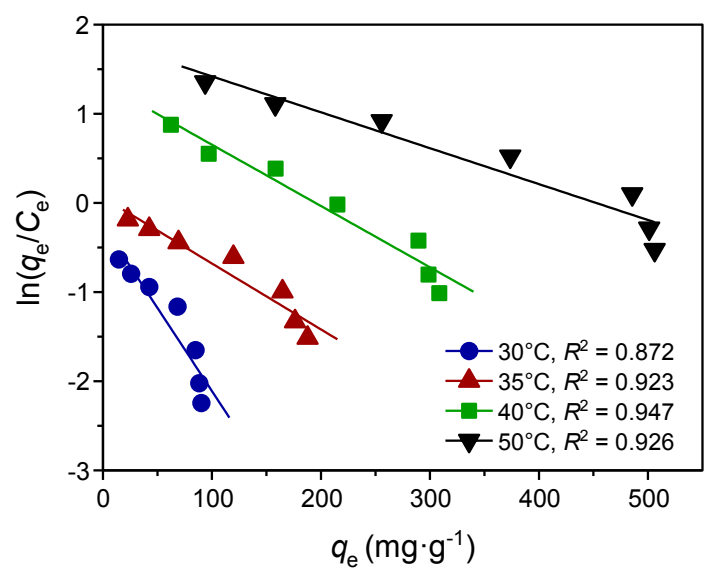

Fig. 11. Elovich-Larionov isotherm for adsorption of MG on UBTL for different temperatures.

\section{Flory-Huggins isotherm}

Flory-Huggins model describes the degree of surface coverage nature of the adsorbate onto the adsorbent. The linear form of Flory-Huggins model is presented by Eq. 13 as [40],

$$
\ln \frac{\theta}{C_{\mathrm{o}}}=\ln k_{\mathrm{FH}}+\alpha_{\mathrm{FH}} \ln (1-\theta)
$$

where, $\theta=\left(1-C_{\mathrm{e}} / C_{\mathrm{o}}\right)$ is the surface coverage of the adsorbent by the adsorbate, $\alpha_{\mathrm{FH}}$ is the number of adsorbate occupying in adsorption sites, $K_{\mathrm{FH}}$ is Flory-Huggins equilibrium constant. The values of $K_{\mathrm{FH}}$ and $\alpha_{\mathrm{FH}}$ are determined from the intercept and the slope of the plot as $\ln \left(\theta / C_{\mathrm{o}}\right)$ vs $\ln (1-\theta)$, respectively shown in Fig. 12 and presented in Table 1. 
Table 1. Comparison of the parameters derived from different isotherm models for different processing temperatures at $\mathrm{pH} 2.0$.

\begin{tabular}{|c|c|c|c|c|c|}
\hline \multirow[b]{2}{*}{$\begin{array}{l}\text { Isotherm } \\
\text { Model }\end{array}$} & \multirow[b]{2}{*}{ Parameters } & \multicolumn{4}{|c|}{ Temperatures $\left({ }^{\circ} \mathrm{C}\right)$} \\
\hline & & 30 & 35 & 40 & 50 \\
\hline \multirow{3}{*}{ Langmuir } & $q_{\mathrm{m}}\left(\mathrm{mg} \cdot \mathrm{g}^{-1}\right)$ & 109.890 & 250.000 & 357.143 & 588.235 \\
\hline & $b \times 10^{3}\left(\mathrm{~L} \cdot \mathrm{mg}^{-1}\right)$ & 6.046 & 3.779 & 7.203 & 7.759 \\
\hline & $R^{2}(-)$ & 0.995 & 0.996 & 0.998 & 0.998 \\
\hline \multirow{3}{*}{ Freundlich } & $K_{\mathrm{f}}\left(\mathrm{L} \cdot \mathrm{mg}^{-1}\right)$ & 3.018 & 3.497 & 15.481 & 24.138 \\
\hline & $1 / n$ & 0.533 & 0.616 & 0.465 & 0.477 \\
\hline & $R^{2}(-)$ & 0.943 & 0.967 & 0.962 & 0.952 \\
\hline \multirow{3}{*}{ Temkin } & $B$ & 24.056 & 51.623 & 76.273 & 126.422 \\
\hline & $A$ & 0.061 & 0.046 & 0.077 & 0.080 \\
\hline & $R^{2}(-)$ & 0.979 & 0.984 & 0.986 & 0.984 \\
\hline \multirow{4}{*}{$\begin{array}{c}\text { Dubinin- } \\
\text { Radushkevich }\end{array}$} & $q_{\mathrm{m}} \times 10^{3}\left(\mathrm{~mol} \cdot \mathrm{g}^{-1}\right)$ & 1.100 & 2.471 & 2.768 & 4.795 \\
\hline & $r\left(\mathrm{~mol}^{2} \cdot \mathrm{k}^{-1} \cdot \mathrm{J}^{-2}\right)$ & 5.5 & 6.1 & 4.4 & 4.3 \\
\hline & $E\left(\mathrm{~kJ} \cdot \mathrm{mol}^{-1}\right)$ & 0.302 & 0.286 & 0.337 & 0.341 \\
\hline & $R^{2}(-)$ & 0.966 & 0.984 & 0.980 & 0.982 \\
\hline \multirow{3}{*}{ Harkin-Jura } & $B_{\mathrm{HJ}}$ & 2.75 & 2.70 & 4.00 & 3.33 \\
\hline & $A_{\mathrm{HJ}}$ & 416.67 & 1000 & 10000 & 16666.67 \\
\hline & $R^{2}(-)$ & 0.679 & 0.664 & 0.744 & 0.705 \\
\hline \multirow{3}{*}{ Halsey } & $n_{\mathrm{H}}$ & -1.88 & -1.62 & -2.15 & -2.10 \\
\hline & $k_{\mathrm{H}} \times 10^{2}$ & 12.53 & 13.16 & 0.28 & 0.12 \\
\hline & $R^{2}(-)$ & 0.943 & 0.967 & 0.962 & 0.953 \\
\hline \multirow{3}{*}{$\begin{array}{l}\text { Elovich- } \\
\text { Larionov }\end{array}$} & $q_{E}$ & 53.76 & 135.14 & 144.93 & 250.00 \\
\hline & $k_{\mathrm{E}} \times 10^{3}$ & 14.54 & 7.86 & 26.38 & 24.76 \\
\hline & $R^{2}(-)$ & 0.872 & 0.923 & 0.947 & 0.926 \\
\hline \multirow{3}{*}{ Flory-Huggins } & $K_{\mathrm{FH}} \times 10^{6}\left(\mathrm{mg} \cdot \mathrm{g}^{-1}\right)$ & 2.39 & 2.80 & 12.75 & 18.22 \\
\hline & $\alpha_{F \mathrm{H}(-)}$ & -194.75 & -127.8 & -45.74 & -28.93 \\
\hline & $R^{2}(-)$ & 0.998 & 0.996 & 0.981 & 0.991 \\
\hline
\end{tabular}

\subsection{Thermodynamics of adsorption}

The maximum amount adsorbed of MG on UBTL was determined from the best fitted Langmuir plots for different temperatures at $\mathrm{pH}$ 2.0. Fig. 13 shows the variation of amount adsorbed with temperature known as adsorption isobar which indicated that the amount adsorbed increased with increasing temperature i.e. the process is endothermic.

The Langmuir constant values, $b$ for MG adsorption on UBTL were also calculated for different temperatures by using Langmuir equation. These were used to calculate the thermodynamic parameters: $\Delta G_{\text {ads }}, \Delta S_{\text {ads }}$ and $\Delta H_{\text {ads }}$ by using Eq. 13 and 14 [41-42] as a plot of $\ln b$ vs. $1 / T$ as shown in Fig. 14. 


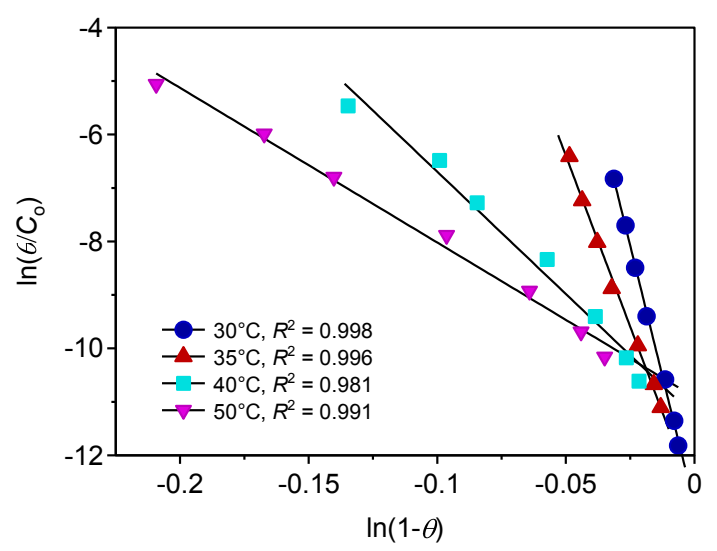

Fig. 12. Flory-Huggins isotherm for adsorption of MG on UBTL for different temperatures.

$$
\begin{aligned}
& \ln b=\frac{\Delta S_{\mathrm{ads}}}{R}-\frac{\Delta H_{\mathrm{ads}}}{R T} \\
& \Delta G_{\mathrm{ads}}=-R T \ln b
\end{aligned}
$$

where, $R$ is the molar gas constant $\left(8.314 \mathrm{~J} \cdot \mathrm{K}^{-1} \cdot \mathrm{mol}^{-1}\right), T$ is the absolute temperature $(\mathrm{K}), b$ is

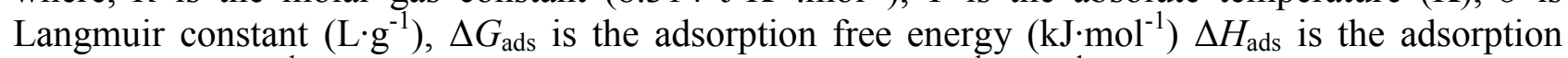
enthalpy $\left(\mathrm{kJ} \cdot \mathrm{mol}^{-1}\right)$ and $\Delta S_{\text {ads }}$ is the adsorption entropy $\left(\mathrm{J} \cdot \mathrm{K}^{-1} \cdot \mathrm{mol}^{-1}\right)$. The values $\Delta H_{\mathrm{ads}}$ and $\Delta S_{\mathrm{ads}}$ were estimated from the slopes and intercepts of the plot of $\ln b$ versus $1 / T$ as shown in Fig 14 . Again, $\Delta G^{o}$ value is computed by using Eq. 14. The values of $\Delta G_{\text {ads }}, \Delta H_{\text {ads }}$ and $\Delta S_{\text {ads }}$ of MG adsorption on UBTL at different temperatures are presented in Table 2 . The positive values of $\Delta G_{\text {ads }}$ and $\Delta H_{\text {ads }}$ indicated the adsorption of MG was non-spontaneous and endothermic at $\mathrm{pH} 2.0$. The positive values of $\Delta S_{\text {ads }}$ indicated that the fragmentation of large MG molecules might occur during adsorption process.

\subsection{Effect of electrolytes and adsorption mechanism}

The effect of electrolytes on the adsorption of MG onto UBTL was carried out to identify the involvement of protonation/deprotonation mechanism or electrostatic force of attraction between MG and UBTL. The batch adsorption experiments were performed in presence of two electrolytes $\left(\mathrm{NaCl}\right.$ and $\mathrm{NaNO}_{3}$ ) with different concentrations for a same concentration of MG. A plot of equilibrium amount adsorbed, $q_{e}$ vs concentration of electrolytes is presented in Fig. 15.

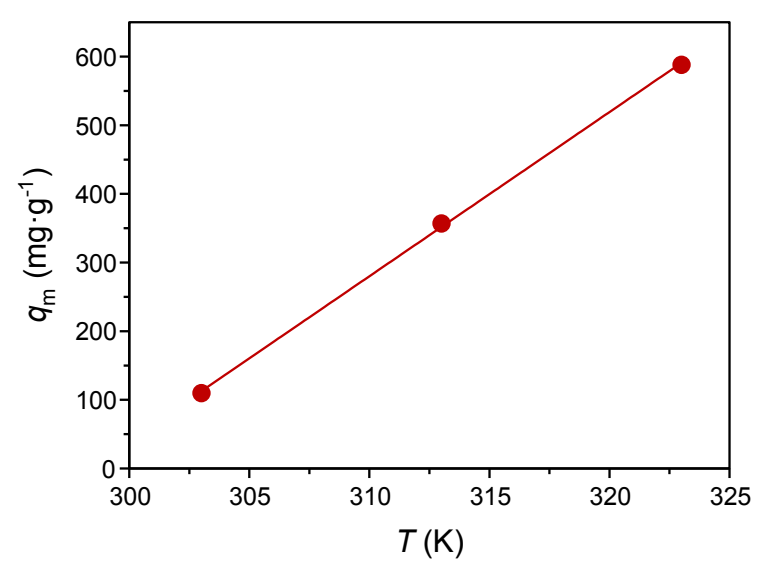

Fig. 13. Adsorption isobar for adsorption of MG on UBTL at $\mathrm{pH} 2.0$

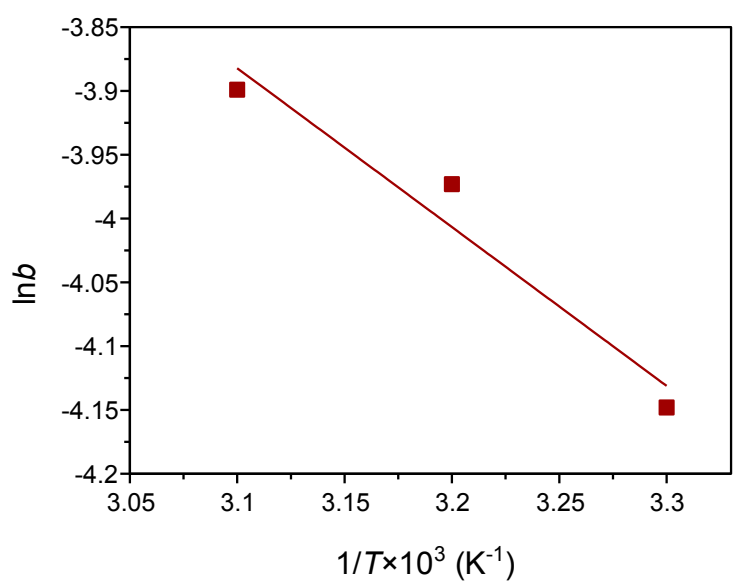

Fig. 14. A plot of $\ln b$ vs $1 / T$ for adsorption of MG on UBTL at pH 2.0 
Table 2. The thermodynamic parameters for MG adsorption on UBTL at $\mathrm{pH} 2.0$ for different temperatures.

\begin{tabular}{cccc}
\hline $\begin{array}{c}\text { Temperature } \\
(\mathbf{K})\end{array}$ & $\begin{array}{c}\Delta \boldsymbol{H}_{\text {ads }} \\
\mathbf{k J} \cdot \mathbf{m o l}^{\mathbf{1}}\end{array}$ & $\begin{array}{c}\Delta \boldsymbol{G}_{\text {ads }} \\
\mathbf{k J} \cdot \mathbf{m o l}^{\mathbf{1}}\end{array}$ & $\begin{array}{c}\Delta \boldsymbol{S}_{\text {ads }} \\
\mathbf{J} \cdot \mathbf{m o l}^{\mathbf{1}} \mathbf{K}^{\mathbf{1}}\end{array}$ \\
\hline 303 & & +10.45 & \\
313 & +10.35 & +10.34 & -22.13 \\
323 & & +10.47 & \\
\hline
\end{tabular}

The figure shows that at $\mathrm{pH} 2.0$, the amount adsorbed is exponentially decreased with the increase of electrolyte $(\mathrm{NaCl})$ concentration which supports the involvement of protonation mechanism in the adsorption due to the faster competitive adsorption of negative electrolytes $(\mathrm{NaCl})$ than that of the neutral MG molecule to the positive site of UBTL surface as shown in Fig. 16. Same figure shows that the amount adsorbed is exponentially increased with increasing the concentration of $\mathrm{NaNO}_{3}$ electrolytes. This observation might be due to the formations of positive site on $\mathrm{NO}_{3}{ }^{-}$ions after adsorption on positive UBTL surface by delocalization of lone pair of electrons on rest two

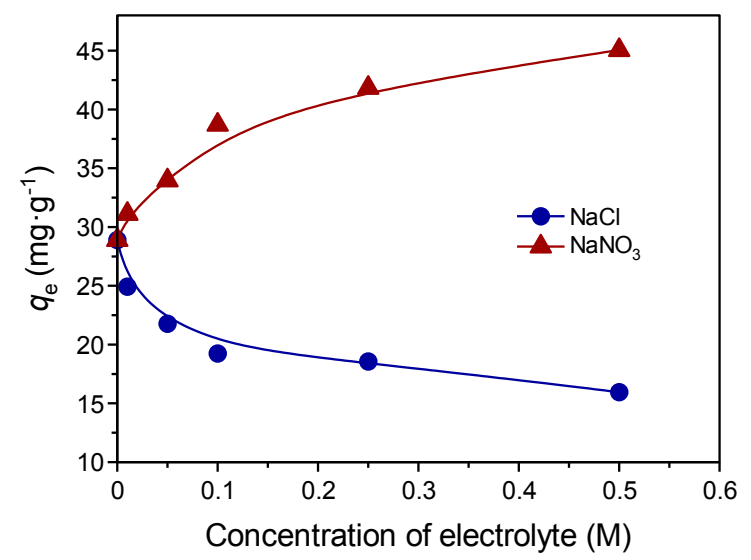

Fig. 15. Variation of equilibrium amount adsorbed $\left(q_{\mathrm{e}}\right)$ with concentration of electrolytes for the adsorption of $\mathrm{MG}$ on UBTL at initial $\mathrm{pH} 2.0$ and $30 \pm 0.2^{\circ} \mathrm{C}$.<smiles>CC(C)O[N+](=O)[O-]</smiles>
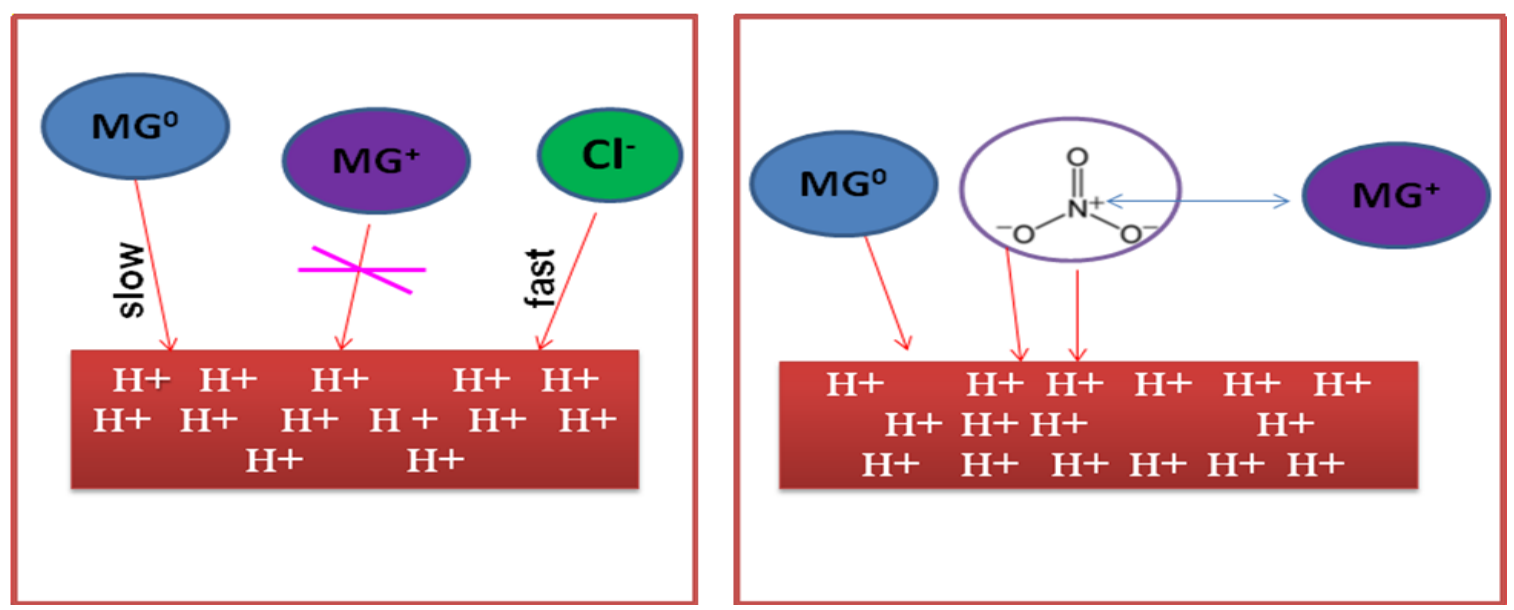

Fig. 16. Proposed mechanism for the adsorption of MG on UBTL based on the effect of two electrolytes at $\mathrm{pH} 2.0$. 
oxygen atoms of $\mathrm{NO}_{3}{ }^{-}$ions. $\mathrm{MG}$ exists in $\mathrm{MG}^{+}$and $\mathrm{MG}^{\circ}$ form at lower $\mathrm{pH}$. As a result, the positive sites of MG repelled by positive sites of adsorbed $\mathrm{NO}_{3}{ }^{-}$ions but partially attract the neutral MG to surface. As a result, the amount adsorbed of neutral MG increased with increasing the concentration of $\mathrm{NO}_{3}{ }^{-}$ions on the less positive UBTL surface as shown in Fig. 16.

\section{Conclusions}

The results of this investigation showed that the equilibrium adsorption of MG on UBTL follows Langmuir comparatively batter than other isotherms. The maximum adsorption capacity was found $110 \mathrm{mg} \cdot \mathrm{g}^{-1}$ at $30^{\circ} \mathrm{C}$, which was increased with increasing temperature. Thermodynamics parameters: $\Delta G_{\text {ads }}, \Delta H_{\text {ads }}$ and $\Delta S_{\text {ads }}$ of the adsorption suggested that the adsorption is endothermic and less spontaneous. The value of activation energy for the adsorption of MG on UBTL indicated that the process is controlled by physical in nature.

\section{Acknowledgement}

The authors are grateful to the Chairperson, Department of Chemistry, University of Dhaka, Bangladesh for providing facilities to performed the research. The authors also appreciate the financial support of the Ministry of Science and Technology, Bangladesh and UGC of Bangladesh.

\section{References}

[1] E. Sayan, Chem. Eng. J., 119 (2006) 175-181.

[2] N.K.E.M. Yahaya, M.F.P.M. Latiff, I. Abustan, O.S. Bello, M.A. Ahmad, International J. of Engineering and Technol., 11 ( 2011) 248-252.

[3] A.R. Khan, Pak. J. Sci. Ind. Res., 45 (2002) 82-85.

[4] G. Sekaran, K.A. Shanmugasundaram, M. Mariappan, , K.V. Raghavan, Indian J. Chem Technol., 2 (1995) 311.

[5] I.A.W. Tan, A.L. Ahmad, B.H. Hameed, J. Hazard. Mater., 154 (2008) 337-346.

[6] A. Ozer, G. Dursun, J. Hazard. Mater., 146 (2007) 262-269.

[7] S. Altenor, B. Carene, E. Emmanuel, J.E. Lambert, S. Gaspard, J. Hazard. Mater., 165 (2009) 1029-1039.

[8] B. Girgis, S. Abdel-Nasser, A. El-Hendawy, Micropor. Mesopor. Mater., 52 (2002) 105-117.

[9] N.M. Haimour, S. Emeish, Waste Manage., 26 (2006) 51-60.

[10] T. Yang, L.A. Chong, Mater. Chem. Phys., 100 (2006) 438-444.

[11] B.P. Chandran, Water Res., 36 (2002) 2824-2830.

[12] M.A. Hossain, M. Kumita, Y. Michigami, S. Mori, J. Chem. Eng. Jpn., 38 (2005) 402-406.

[13] M.A. Hossain, M. Kumita, Y. Michigami, S. Mori, Adsorption, 11 (2005) 555-564.

[14] M.A. Hossain, K. Mikio, S. Mori, African J Pure and Appl. Chem. 4(7) (2010) 135-141.

[15] M.A. Hossain, M.L. Hossain, International J. Recent Sci. Res. 4(10) (2013) 1575-1579.

[16] M.A Hossain, M.S. Alam, Iran. J. Environ. Health. Sci. Eng., 9 (2012) 2-15.

[17] M.A. Hossain, M.L. Hossain, Int. J. Adv. Res. 2(4) (2014) 360-374.

[18] M.A. Hossain, T.A. Hassan, Orbital: Elec. J. Chem., 5(3) (2013) 148-156.

[19] M.A. Hossain, M.A. Rahman, Orbital Elec. J. Chem., 4(3) (2012) 187-201.

[20] M.A. Hossain, Z. Hasan, Dhaka Univ. J. Sci., 59(2) (2011) 193 - 197. 
[21] I. Langmuir, I., J. Am Chem Soc., 40 (1918) 1361-1403.

[22] M.A. Ackacha, M. Drmoon, International Confer. on Transport, Environ. and Civil Eng., Kuala Lumpur, Malaysia, 2012.

[23] B.K. Suyamboo, R.S. Perumal, Iranica J. of Energy \& Environ., 3(1) (2012) 23-34.

[24] M. Hachkar, A.B. Karim, B. Mounir, M. Bakasse, A. Yaacoubi, Canad. J. Environ. Construc. and Civil Eng., 2 (2011) 2-14.

[25] N. Gupta, A.K. Kushwaha, M.C. Chattopadhyaya, J. Chem. Pharm. Res., 2(6) (2010) 34-45.

[26] T.W Weber, R.K. Chakkravorti, AlChE. J., 20 (1974) 228-238.

[27] V. Vijayakumaran, S. Arivoli, J. Mater. Environ. Sci., 33 (2012) 525-536.

[28] H. Freundlich, Phys. Chem. Soc., 40 (1906) 1361-1368.

[29] O. Tunc, H. Tanac, Z. Aksu, J. Hazard, Mater., 163 (2009) 187-198.

[30] M.J. Temkin, V. Pyzhev, Acta Physiochim, URSS., 12 (1940) 217-222.

[31] V. Mehdi, A. Marjan, Z. Marjan, J.Y. Bita, J. Phys. Theor. Chem. 7(2) (2010) 95-104.

[32] B. Emrah, O.Z. Mahmut, S.I. Ayhan, Microporous and Mesoporous Materials., 115 (2008) 234-246.

[33] M.H. Baek, C.O. Ijagbemi, D.S. Kim, J. Hazard. Mater., 174 (2010) 746-755.

[34] H. Tahir, Q. Jahanzeb, M. Sultan, Afr. J. Biotechnol., 7(21) (2008) 3906-3911.

[35] S. Veli, B. Alyuz, J. Hazard. Mater., 149 (2007) 226-233.

[36] A. Kausar, H.N. Bhatti, G. MacKinnon, Colloids and Surfaces B., 111 (2013) 124-133.

[37] C.A. Basar, J. Hazard. Mater., 135 (2006) 232-241.

[38] S.Y. Elovich, O.G. Larionov, Izv. Akad. Nauk. SSSR, Otd. Khim., 2 (1962) 209-218.

[39] B.A. Fil, M.T. Yilmaz1, S. Bayar, M.T. Elkoca, Brazilian J. Chem. Eng., 31(1) (2014) 171182.

[40] C. Theivarasu, S. Mylsamy, E-J. of Chem., 8(S1) (2011) 363-371.

[41] K. Ada, A. Ergene, S. Tan, E. Yalcin, J. Hazard. Matter., 165 (2009) 637-644.

[42] B.K. Nandi, A. Goswami, M.K. Purkait, Appl. Clay. sci., 42 (2008) 583-590. 